\title{
Infant feeding: medicalization, the state and techniques of the body
}

\section{Introduction}

This volume examines infant feeding in relation to three core concerns: its medicalization, normalization by technologies of the state, and its regulation by techniques of the body. There are clear overlaps between these areas, but this three-tiered approach allows for a respective focus on 1) how medicine exercises authority over areas of life not previously considered medical; 2) the internalisation of the state's disciplinary regimes and their perpetuation through the use of normalising judgement in practice; and finally, 3) the micro-levels, and minutiae practices of everyday infant nurture, and what these say about the development of specific types of people. In so doing, we build on a stream of feminist scholarship on breastfeeding since the 1980s, but we also diverge, in that our focus is not only breastfeeding but more broadly the nourishment of infants - be this from the birth mother's breasts, or through what Tanya Cassidy (2015) has recently called 'lactational surrogacy', including wet-nursing and milk sharing as well as infant milks derived from other sources, animal and vegetable. To this, we expand our view beyond milks to include the feeding of other foodstuffs and the absorption of nourishment through massage, bathing, the reciting of blessings and even, in one case, rubbing the underbelly of the tongue. In canvassing these other-than-oral nourishing practices, we highlight the epistemologies that underscore them, and problematise the ontological premises of the concept of nurture itself.

To date, much feminist scholarship on infant feeding has been concerned with the controversies between breast and commercial formula feeding, and rightly so given the ways in which formula feeding has so often been demonstrated to ensnare women into relations of medical and state control, capitalist markets, industrial conceptions of time and the body, and not least, given the devastating consequences for infant survival. Another generation, 
distrustful of the medical establishment, the state and multinational corporations, turned to breastfeeding as the 'natural' alternative which offered benefits for infant and maternal health. Yet these efforts at breastfeeding advocacy have also been folded into systems of medical and state authority, as well as social hierarchies of race and class, in ways that have been demonstrably problematic. Aside from the question of breast or bottle there are, of course, a great many other feeding practices that have been drawn upon to nourish infants across different times and places, which have slipped out from view. In this volume, we offer fresh empirical material to engage these long-standing controversies, but from these three vantage points which, we suggest, open out new routes of inquiry.

\section{A whistle-stop review}

Reviewing the foundational body of work on infant feeding, chiefly on breastfeeding, the field divides into historical studies and contemporary analyses. Among the historical studies, the most renowned is Valerie Fildes' (1986) Breasts, Bottles and Babies: A History of Infant Feeding. This book was ground-breaking in bringing together paediatric, midwifery and religious texts and child-rearing advice books alongside private notes, letters and diaries between 1500 and 1800. Fildes documented the detail of infant feeding patterns in Western Europe, highlighting shifts towards an earlier initiation of breastfeeding, the spread of wetnursing and then, at the end of the period, its progressive replacement by artificial feeding. She linked these changes to new medical recommendations, the pronouncements of the Church, the trickling-down of fashions from the higher classes, and the forces of economic circumstance and gender and generational hierarchies at the level of the household. Fildes insists on the importance of this period because, as European domination spread, their norms of infant feeding demonstrably influenced practices across the rest of the world (a point developed by King and Ashworth, 1987, and see below). 
The United States has also presented a very rich site for historical investigation. Rima Apple's (1987) Mothers and Medicine: A Social History of Infant Feeding documented the shift from breastfeeding to artificial bottle feeding in late $19^{\text {th }}$ and early $20^{\text {th }}$ century America, emphasizing the increasingly specialised profession of paediatrics and the expansion of commercial infant foods, in a context where paediatricians controlled women's understanding of the complicated 'percentage' formulas only they could administer as breastmilk substitutes. Janet Golden's (2001) A Social History of Wet Nursing in America: From Breast to Bottle explored the displacement of wet-nursing by artificial feeding, detailing the economic relationships between wet-nurses, their employers, physicians, and the often tragic consequences for the survival of wet-nurses' own birth children. Most recently, Amy Bentley's (2014) Inventing Baby Food examines the proliferation of commercial baby foods in post-war America, seeing these canned foods as apt preparation for the highly processed, minimally nutritious and calorie-dense food cultures of the United States.

Among the contemporary analyses, Gabrielle Palmer's (1988) The Politics of Breastfeeding offered a searing critique of the marketing of infant formula companies in the developing world and of the distorting effects of corporate-funded research on our understandings of the health effects of breast versus bottle feeding. Whilst agreeing about the problematic ways in which women have been controlled by the medical establishment, state authorities and infant formula corporations, Vanessa Maher's (1992) The Anthropology of Breastfeeding added a critique of breastfeeding promotion efforts for disregarding the interests of mothers and treating them as a mere vehicle for improving the health of infants. Maher emphasized the recurrent finding that infant health in developing countries is determined more powerfully not by whether a baby was breastfed or not, but by the wealth of the household she is born into. She charged that, in situations where women and children are already side-lined in the allocation of food and other scarce resources, admonitions that 
women breastfeed their infants seemingly expect women to deplete their bodily resources in order to compensate impossibly for the inequalities of their societies and households.

In the mid-1990s, attention turned to the inequalities between women that are, arguably, exacerbated by the ways in which breastfeeding advocacy is taken up. Treading between these controversies, Linda Blum (1993) argued in the context of the United States that it is problematic if the positive, sensuous and non-commodified experience of one's body that breastfeeding can offer women is a 'luxury' enjoyed chiefly by White, middle class, married women. Similarly, Penny van Esterik (1994) endorsed breastfeeding advocacy as a feminist prerogative, but highlighted how breastfeeding involves contradictions that the women's movement is still grappling with, such as, perhaps most stubbornly, the tensions between liberal and maternalist politics (later, see also Hausman, 2004, and Wolf, 2006). The mid-1990s also saw a re-positioning of biology in the debates. Biological anthropologists Stuart-Macadam and Dettwyler (1995) warned of "the perils of ignoring the "bio" factor of the biocultural equation' (p.1). Obermeyer and Castle's (1996) discussion of the 'insufficient milk syndrome' drew links between the biological mechanisms involved in the supply of milk, behavioural factors like the number of feeds per day, length of feeds and intervals between them, and wider social inequalities such as patriarchal family structures, poverty and powerlessness. Mara Mabilia's (2002) study of the Wagogo in Tanzania endorsed the biocultural reality of Gogo women's fears about the heating and spoiling effects of postpartum sexual activity on their breastmilk by linking these fears to the inhibitory effect of stress on the 'let-down reflex'. Attempting to bridging the gap between our ancestral heritage and current practice, Ball and Russell's (2012) work suggests how 'new cultural environments' have compromised the care conditions that characterised 'ancestral environments' pointing out that emulating some of the latter is 'crucial to the operation of our mammalian, primate, and hominid physiology’ (p.255). 
More recently, feminist scholarship has moved further to critique the idea of breastfeeding as 'natural'. Liamputtong's (2007) collection Infant Feeding Practices: A Cross-Cultural Perspective and Dykes and Hall-Moran's (2009) Infant and Young Child Feeding highlight contradictions whereby breastfeeding, though constructed as a 'natural activity', is simultaneously also deemed to need improvement through the assistance of experts. Furthermore, the studies in these collections show that for a great many women across the world, 'natural' breastfeeding is only enabled by the intervention of manifold technologies ranging from the consumption of galactogogues to the pumping of milk to increase supply (see especially Avishai, 2007). Faircloth (2013) critiques the contradictions between British 'attachment parents' discourse about long-term breastfeeding as an evolutionary inheritance from our hominid past, and their 'cherry-picking' of the hominid inheritance as part of their identity work in affiliating to their particular 'parenting camp'. If the notion of breastfeeding as a 'natural' has been demonstrated to be a veneer for ideological work, then, recent work suggests, so is the doctrine that 'breast is best'. In her critical appraisal of research on the health benefits of breastfeeding for infants, Wolf (2011) finds the medical research to be surprisingly equivocal, at least in North America. She charges that this has not filtered into public culture because of the obsession with personal responsibility and perfect mothering.

Mirroring the swell of historical interest in wet-nursing, the most recent turn in feminist scholarship on breastfeeding seems to emphasize breastfeeding as a collective accomplishment rather than the act of a birth mother-infant dyad alone, with Shaw and Bartlett's (2010) collection Giving Breastmilk shining a light on breastmilk exchange, Tomori's (2014) Night-time Breastfeeding: An American Cultural Dilemma emphasizing the significance of husbands/fathers in mothers' breastfeeding trajectories, and Cassidy and El Tom's (2015) collection Ethnographies of Breastfeeding including a number of case studies 
of milk sharing and milk banking as instances of 'lactational surrogacy'. Concepts of giving have moved centre-stage. While Mabilia (2005), drawing from Marcel Mauss (1969), discusses the ambivalent gifting relationship established between the mother and infant as a result of the exchange-demand of breastfeeding, Giles (2010) takes up Jacques Godbout's (1998) The World of the Gift to explore how the human subject is formed through ethical relations, as interpersonal reciprocity and openness to others transform strangers into familiars. Her argument is directed to those who give milk to other mothers. However, it may also be a useful way of understanding how infant-others are made into kin (Carsten, 1997, Vilaça, 2002, de Graeve and Longman, 2013). Thus, even beyond Euro-American ontologies of biomedical ethics, commoditization and altruism in the sharing of breastmilk, the wider (environmentally-extended) ethics of an enlarged sharing community, based on a cosmovision of mutual trust and reciprocity in which infants also engage, is one consistently brought to bear in discussions of child development and feeding in contexts of subsistence sociality (see inter alia Overing, 1989, Gow, 1989, Hewlett et al., 2000, Bird-David, 2008). In such contexts, the sharing of breastmilk with non-humans is common practice (see BirdDavid 2008, p.534). This, Bird-David (2008) argues, breaks down any clear cut distinction between the human and the animal subject and, by virtue of its engendering of a new relationship, dissolves the subject and object hierarchy of feeding. In these contexts, she suggests 'sharing' with, rather than nurturing, is a more apt descriptor of infant feeding. As this review skips across three decades of scholarship, it becomes clear that the work of historicizing and critiquing infant feeding and interventions has been and continues to be, very literally, vital. This volume seeks to enter into dialogue with this corpus of work, bringing together a collection of fresh empirical studies of infant feeding by emerging scholars. Our view includes historical studies over a period of two centuries, and contemporary studies comparing between sites in Europe, South Asia, Latin America and 
Africa. We look at the nourishment of infants from the earliest stages of gestation through to older babies who are fully weaned and fed on solids. Whilst our perspectives reflect these controversies over infant feeding and interventions, we do not shy away from commenting on our differences. We offer a three-pronged approach to infant feeding which leaves, we suggest, fruitful opportunities for further dialogue and analysis.

\section{Medicalization}

The first of our core concerns is medicalization, understood following Conrad and Schneider (1980) as the process by which what were once considered normal human events and problems, such as birth, ageing or menopause, come to be viewed as medical conditions. In this process, medicine increasingly permeates daily life. The concept of 'authoritative knowledge', given to us by Brigitte Jordan (1978) - the founding mother of the anthropology of reproduction who, sadly, passed away whilst we were drafting this introduction - is also pertinent here. This she defined as the progressive gains in cultural authority, economic and political influence of the medical profession, and the simultaneous deligitimization of other forms of knowledge - tacit, embodied or simply non-medical (see Davis-Floyd and Sargent, 1997). Scholars have shown us that the medicalization of birth as high-risk has legitimized unnecessary technological interventions and encouraged careful monitoring, control and scheduling of the bodily practices surrounding birth (Davis-Floyd, 1990).

It was often noted by breastfeeding scholars, with some frustration, that Emily Martin's (1987) epochal critique of the medicalization of women's reproductive bodies contained scarcely any discussion of breastfeeding. But other work has amply filled in this picture. The intensely medicalised experiences of many new mothers has, Millard (1990) argues, 'encouraged receptivity to biomedical advice on breastfeeding and tended to stifle overt resistance by those less inclined to adhere to medical advice' (p.212). Emphasising a 
generalised distrust in bodily signals, Millard demonstrates how paediatric advice centres on the scheduling of breastfeeding, highlighting that even within the ill-defined notion of feeding-on-demand, the length of time and intervals between feeds continue to be themes of central importance. This is a reflection, she suggests, of the wider cultural importance of time and the assumption of a clock-like regularity in bodily processes, including infant hunger and the maternal production of milk. Similarly, Dykes' (2006) work with new mothers in hospitals demonstrates that the breastfeeding body is conceived by Western medicine through the industrial metaphor of the machine. The language used by health professionals, with their notions of efficient 'demand' and 'supply', is of the factory production line; their advice and questions are framed in terms of frequencies, duration, size and output of milk. Mirroring Martin's Marxist analysis of the separation of women's labouring bodies from the products of their labour, Dykes finds women to be alienated from their breastfeeding bodies. They describe their breastmilk as a nutritional and immunological product, rather than talking about breastfeeding as an intimate relational act. They doubt their capacity to supply milk in the right quantity, and are troubled by their babies' seemingly insatiable demand to feed and to suckle at the breast; namely, by their babies' transgression of the industrial organization of time and space. Bartlett (2010a, 2010b) has affirmed the difficulties for breastfeeding mothers that are presented by the medical rationalization of time, production, control and surveillance.

Our volume begins with Margaret Carlyle's historical study of enlightenment France, which engages these ideas in relation to the development of the pompe à sein (the breastpump). Given the ubiquity of these devices in the world today, shown by contemporary ethnographies to be as often a nightmare as a mercy for breastfeeding women, it is fascinating to think to their origins. Carlyle's illustrated exposition rewards us. In France, Carlyle situates the breast-pump amid the public obsession with population decline in the late $18^{\text {th }}$ century, 
which motivated a host of social commentary by intellectuals urging women to 'return to nature'. The object of their critique was wet-nursing, which was certainly widespread among the upper classes at that time, and perhaps well-established too in other social strata. Wetnursing had been observed to have catastrophic effects on infant survival, and the late $18^{\text {th }}$ century saw a proliferation of tracts demonizing wet-nurses as weak, filthy, diseased, ignorant and mercenary. To the ends, Carlyle documents a number of concurrent shifts lending towards a medicalization of breastfeeding. First, reflecting the received notion of breastfeeding as 'a learned technique, requiring more tacit knowledge than instinct alone', was the development of a small market in fee-paying breastfeeding coaching, as exemplified by the courses offered by the accoucheur (man-midwife) of Queen Marie Antoinette. Second was a flourishing of scientific research into the properties of cow's, goat's, donkey's and other animals' milks, enabled by developments in food chemistry. Despite their scientific interest, the chemists and physicians who carried out this work balked at the idea of feeding infants animal milks because of deeply ingrained ideas about the communicative qualities of milk and its capacity to transmit beastly characteristics. Here, then, enters the breast-pump, as third development in the period, the most interventionist among a repertoire of commercial feeding aids that were being newly marketed, including feeding spoons, cups with spouts and vessels with double openings. The Parisian breast-pump was devised by a tinker, Jacques Bianchi, inspired by his encounters with German prototypes. The pump was intended to help disgorge breasts, 'prime' distended nipples, alleviate pain and increase milk supply. Recalling Martin's analysis of medical metaphors of the body, it is poignant that Bianchi's pump evolved, apparently, out of his investigations into barometry. As Carlyle points out, the pump exemplifies a view of the woman's body as a machine, 'subject to the laws of physics and whose faults could be corrected through instrumental manipulation'. Hot on the heels of 
Bianchi's model were cheaper rivals, which expanded the market beyond well-to-do Parisians.

Enlightenment France offers us a case where the medicalization of infant feeding accompanied a movement towards breastfeeding by the birth mother, rather than a direct move towards artificial feeding with modified animal milks, as we saw in the historical literature on Britain and the United States. Nonetheless, we can discern familiar intersections between expanding medical authority, women's dependence on the mediations of technology, and progressive medical commercialisation. The archival sources that Carlyle examines cannot shed much light on the reception of this technology by women. However, she points out that the development and expansion of these technologies allows us to see an equivocality in women's reception of the prescriptive literature urging them to breastfeed. There were women who attempted to do so, but encountered difficulties with their encultured bodies in doing so, a point to which we return below. She argues that the continuation of wet-nursing well into the Napoleonic period indicates the continuation of practices that ran counter to medical and civic authority.

Our next contribution, by Ranjana Saha, sketches out some parallel developments in late $19^{\text {th }}$ century, early $20^{\text {th }}$ century Bengal. In Saha's paper we can see, with greater clarity than ever before, how British colonization led to a diffusion of British norms of infant feeding in India, but she also traces out the tensions and unpredictability of this cultural interaction. Western medical ideas about infant feeding were taken up by nationalist reformers and medical practitioners in varied ways to improve community and national health, often challenging the colonial project itself.

The prescriptive literature in Bengal has often been studied by historians of colonial India. Bengal was, as Chatterjee (1993) influentially demonstrated, the intellectual crucible of Indian nationalism, where a nationalist vision of modern India was elaborated, bringing 
together the technological developments associated with the British in the public domain, with the authentically Indian in the private, as indexed by the Bengali bhadramahila (respectable woman). The domestic manuals that flourished for the bhadramahila, based on their English prototypes, have also been studied. Saha's richly-illustrated paper offers us a novel problematization of the centrality of breastfeeding to imperial and nationalist discourses on motherhood and childcare, and the colonial 'mothercraft' project, using many previously unexplored sources. She examines an archive of midwifery and child-care manuals written by British medical observers, by Bengali practitioners of Western medicine and by indigenous practitioners of Ayurveda, which was undergoing a process of rearticulation through communalization, nationalization, and modernization.

Saha elucidates the place of infant feeding within the colonial project of science as a 'civilizing mission'. The colonial authorities aimed to discipline Indian mothers, whom they maligned as indulgent and insufficient, and generally to 'clean up and rationalize the entire range of "sacred" versus "polluting" ideas surrounding pregnancy, childbirth and postpartum care'. Ignoring the prevalence of colostrum avoidance in Britain until only shortly before these texts were penned, and stressing the element of colonial difference, the colonial 'civilizing missions' decried this practice as irrational, and advocated breastfeeding from birth onwards, condemning Indian practices of prelacteal ghutti purges with honey, butter or animal milks as 'filthy' and 'dangerous'. Dismayed too by Indian women's indulgence of their child's cries, their constant offering of the breast and prolonged lactation - again, common practice in Britain until the $18^{\text {th }}$ century - British writers advocated scheduled feeding by the clock and earlier weaning, with a prize-winning medical manual devoting nearly an entire chapter to infant care, addressing the 'symptoms of over-suckling'. Meanwhile, Bengali medical authors picked up the challenge of Western medical ideas in varied ways. Fascinatingly, Bengali authors also drew invidious comparisons between British 
memsahibas, whom they characterized as having a dislike for breastfeeding, and the breastfeeding bhadramahila mothers (of boys), emphasizing their virtuous 'purity' within Hinduized nationalist frames. This ode to the bhadramahila down-played the prevalence of wet-nursing, which was well established in wealthy Bengali families and not only a form of Anglicization. The British, for their side, were anxious about the disastrous effects of 'the tropics' on the memsahibas' capacity to breastfeed. In many texts we see an encouragement to hire 'native' wet-nurses and an envious, implicitly racist stance towards their prodigious milk production, treating them as 'virtual milch cows'. In one medical book from as early as 1828 , the racist contempt for Indian women was more explicit, describing contemptuously the inferiority of the breastmilk of native dhyes. The indexing of racist ideas to women's lactating bodies through civilizational discourse has perhaps never been so rank.

Saha's contribution underlines that colonization led to varied shifts in conceptions and practices of infant feeding in India, supporting Hunt's (1997) conclusion, from her study of the Belgian Congo, that it would be a gross overgeneralization to assume that colonial rule led simply to an expansion of artificial feeding by commercial milks. Nonetheless, we do also see an expansion in markets for imported galactagogues and alternative infant milks, as well as indigenous products, amidst concerns about the adulteration of cow and buffalo milk.

Our first two historical studies attend to archives of prescriptive texts and advertisements for products, telling us much about the prerogatives of medical professionals and the authority they wielded based on their scientific expertise, technological superiority and close relationship with commodity markets. The linked authority they drew from offering state services is the subject to which we now turn. Before we do so, however, it is worth hinting here as to what our collection has to say about the blind spots in the story of medicalization of infant feeding, too. Our later contributions, particularly those by Gillespie, Qureshi et al. and Rahman, disrupt the linear narrative about the rise of medical authority by 
exploring the uneven reception of medical framings of infant feeding by people in the vicissitudes of their everyday lives. Our studies show that people may respect the advice of medical professionals not because of their scientific or technical expertise, but because they know and trust them. We also show the continued centrality of kin as sources of knowledge about infant feeding (see also Davis, 2011, Pooley and Qureshi, 2016).

\section{The state}

The second of our core concerns is the way that states have intervened to regulate infant feeding, which we approach through a broadly Foucauldian interest in normalization. Famously, in Discipline and Punish Foucault (1975) described the emergence of a modern form of power that was based not in its ability to threaten spectacularly violent forms of punishment, but in its ability to survey people's conduct and make them discipline themselves. The prison panopticon was the metaphor he chose for this modern wielding of power that worked by making inmates keep check their own conduct, because of the possibility of being overseen by a jailor who is positioned in such a way that he is invisible and therefore may or may not be there. This disciplinary power works to normalize, deter deviance and ultimately produce 'docile bodies'. By contrast, in the first volume of The History of Sexuality Foucault (1984) elaborated his understanding of modern power as not only a force of deterrence or repression, but also a productive force, a discourse which turns people into its own willing subjects. In the expansion of scientific knowledge about population and health in $18^{\text {th }}$ century Europe he identified the emergence of 'biopower', a pastoral power that aims strategically to manage and foster the thriving of some, whilst permitting the demise of others. It works through 'governmentality', those bureaucratic and methods of measuring, classifying and recording through which the conduct of populations is shepherded. The appropriate aspirational attitude of the care-giver is that of collusion, to 
avoid risk and seek safety, lest they be branded deviant or unacceptable. In such contexts, as Millard's (1990) study of scheduled feeding alludes, the absence of a regular schedule is taken as a sign of abnormality on the part of the mother and/or child and departure from it is seen as a sign of inadequacy, creating in mothers the desire to conform and resulting in selfdisciplinary behaviour. Foucault was not only thinking of the state, but other institutions as well. But his observations have certainly been germane for understanding the way that modern states have intervened to normalize infant feeding, ostensibly for the good of the many, but at the cost of extinguishing everything that deviates from the norm, and condemning a few to death.

The historical contributions in our volume rehearse some of Foucault's arguments, and also add nuances. Carlyle's paper, discussed above, perhaps exemplifies the coming into being of 'biopower'. We see the French state becoming increasingly concerned with the fear of depopulation, and the emergence of a new idea of a population, one that is not only a potential army but needs to be provided with pastoral care and guidance. The pronatalist sentiment shared by intellectuals, physicians and state officials undergirded efforts to tackle infant mortality by advocating a turn from wet-nursing and a return to breastfeeding, so supported by maternal education and commercial technologies. Saha's paper on late $19^{\text {th }}$ century Bengal reminds us of Ann Laura Stoler's (1995) argument that Foucault's story about the emergence of 'biopower' overlooks colonial history and the ways in which the techniques of population management that were deployed on the urban poor of the European metropole were piloted simultaneously in Europe's colonies. We see similar moves towards the measuring, classifying and recording of infant feeding by the British in India as at home, and the proliferation of modern colonial state power through nutritional expertise.

The third paper in our collection, by Alice Reid, takes us to early $20^{\text {th }}$ century Britain and explores a uniquely detailed set of records produced by one of the early instantiations of 
municipal health visiting, in the county of Derbyshire. In 1905, William Howarth, the Medical Officer of Health for Derby published a paper finding the survival of hand-fed infants to be alarmingly less than that of breastfed infants. As in France, historians have linked the interest in infant survival and health in Britain to post-Boer war concerns about 'national efficiency'. Birth notification had been made compulsory for midwives, doctors or birth attendants to register a birth since 1837, but permissive legislation in 1907 recommended this to take place much earlier, to allow for a more rapid supervision of new mothers. By 1918, early birth registration was made compulsory. Health visitors went out to each new mother immediately after birth, and then repeatedly until five years of age when the child would be monitored at school. The health visitors were avid promoters of breastfeeding, in a context where hand-fed infants in working class families were typically fed cow's milk. Proprietary dried milks were being developed by physicians, sold by companies like Glaxo and Cow and Gate, and marketed to wealthier, middle class women. The health visitors also instructed mothers in hygienic hand-feeding and infant care or 'mothercraft'.

We know relatively little about the infant feeding practices of working class women in Britain at the period. Reid's analysis shows that in 1917-22, 98\% of Derbyshire women initiated breastfeeding; by three months, $70 \%$ were exclusively breastfed and $30 \%$ mixed-fed; by six months, $53 \%$ were exclusively breastfed; and by one year most were to some extent weaned. Whilst William Howarth had found the mortality of hand-fed infants to be three times that of breastfed, his data used approximate categories for the age of infants. Reid has recalibrated this by the precise age of the infant, and found the mortality of hand-fed infants to be 5.5 times that of breastfed infants, particularly due to wasting diseases. It seems that the health visitors were particularly efficient in visiting vulnerable infants, such as twins and illegitimate births, who were also less likely to be breast-fed. Fascinatingly, Reid is able to show that infants who were visited within 14 days of the birth had a lower likelihood of hand- 
feeding, even though the infants visited early tended to be those whom the health visitors deemed weak, such as twins, illegitimate or otherwise sickly babies. Reid's data thus demonstrate that the health visitors were able to encourage breastfeeding among some of the most vulnerable women, and instruct them how to hand-feed more hygienically.

Reid's paper provides a historical case of municipal health provision intervening to normalize infant feeding in ways that were exceptionally personal and targeted. The health visiting movement is in some ways paradigmatic of Foucauldian 'governmentality', although Reid shows that these health visitors did not seek to impose a single middle class norm on working class mothers: the breastfeeding norm they espoused was more working than middle class at the time, and they were supportive of women who were unable to breastfeed for any reason. And whereas many scholars, following Foucault, have critiqued such policies as extensions of state control over women's bodies, Reid demonstrates that the health visiting programme in early $20^{\text {th }}$ century Derbyshire resulted in concrete benefits for infant survival, particularly because of its support for breastfeeding. The following paper, by Bronwen Gillespie, documents social skews to the benefits that are delivered from state-administered iron sprinkle supplementation for mothers and infants in Highland Peru. As a result, Gillespie is more sceptical of state-sponsored maternal education efforts than Reid.

In the Peruvian Andes, iron-deficiency anaemia is a huge problem affecting $45 \%$ of children up to the age of five. The Peruvian government has been distributing multimicronutrient sprinkles through the national health system. In the rural community where Gillespie worked, this was via a health post established in the 1990s. Mothers may collect the sprinkles for free from the health post, and they are also invited to attend educational courses about infant nutrition and weaning.

Unlike the earlier contributions to our special issue, Gillespie's paper offers a detailed exploration of the reception of state-sponsored infant feeding messages by mothers in their 
everyday lives. Her findings indicate that there was widespread acceptance to nutrition education messages in general. Educated women who were wedded to the project of the modern state, and ambitious that their children become urban professionals and leave the peasant life were particularly receptive to the nutritional advice. In the same way that malnutrition and 'slow wittedness' were understood to pass from mother to baby through the exchange of maternal substances during pregnancy and breastfeeding, mothers who followed the nutritional advice they had received from the health post reported that this produces an alert baby who is 'born with his eyes open'. Through their responsiveness to modern nutritional education, they hoped to build a baby who would grow up to be other than a peasant. Nonetheless, the iron sprinkles were a particular block. Many of the mothers were wary of iron sprinkles because they categorized them as a chemical, unnatural, non-food substance. Many mothers, especially, the poorer, less educated women, avoided the sprinkles altogether and instead fed their children red foods like beets, or blood-based dishes, drawing on indigenous techniques for increasing the blood that are based on humoral perceptions of the body. Gillespie argues that mothers were suspicious of iron sprinkles because of the diffusion of the product through the arms of the government, an entity they saw in the abstract as discriminating against the poor, and in its concrete instantiations, in the persons of local health workers, as patronising and paternalistic. Mothers did not offer such strong resistance to medical products sold commercially through pharmacies, for example.

Gillespie shows us the biases within the Peruvian state's efforts at normalization, and the ways in which the Peruvian national project operates through proliferating categories of constituent inclusion, such as the educated citizen of Lima, and constituent exclusion, as with the uneducated peasant in the Highlands. Rural mothers are cognizant of these violent discourses and respond with pragmatism and ambivalence. They recognize the potential benefits from the health post and make efforts to remain 'in the system', but they also dodge 
some of what the health workers preach and weave other plural medical responses into their health-seeking for their children. As she observes, nutrition behaviour is not only about the acceptance of modern nutritional science, but also a way in which people manage their relationship with the state. Such pragmatic strategies that resist these normalising discourses and practices, common to many already marginalised groups, are arguably indigenous examples of what Ricard Shusterman (2000) has termed 'somaesthetics'.

Qureshi et al. echo Gillespie's findings about ambivalence and pragmatism in the case they examine, of neonatal feeding in the province of Punjab in Pakistan. But there are also differences from the health posts in the Peruvian Andes. Whereas the health workers Gillespie describes were lowlanders from the city, very different from the women they serve, and consequently their interactions with rural women often smacked of condescension and distain, the community maternal and child health workers they worked with in Pakistan are women from the very communities they serve. Qureshi et al. show the health workers themselves to be pragmatic in the nutritional education they offer, tailoring their advice to the domestic situations of the women with whom they work. For example, cognizant that women in poor households are unlikely to command the priority in their family budgets to demand milk, meat and fruit during their pregnancies, they encourage women to eat a double helping of chapatti: less nutritious, but it will provide sustenance to the growing foetus. Community health workers are not then simply mouthpieces for modern nutrition education, but syncretically bringing together biomedical knowledge with ideas that resonate more locally. The context of chronic under-resourcing and the limited functionality of public health services in Pakistan is also pertinent in understanding the reception of nutritional education by pregnant and new mothers. As one health worker complained, 'women only let us into their houses when we have free medicines to offer them from the government. Otherwise they tell us "go away, leave us alone, we know how to have babies"'. Tacit and explicit 
knowledge about infant feeding is communicated very powerfully across generations of kinswomen, and health workers have to work hard to insert themselves within this.

\section{Techniques of the body}

Our final concern is then body techniques of infant feeding. By this, we refer to Marcel Mauss's (1973) essay on techniques of the body, where he points to the repertoire of culturally-patterned postures, gaits and gestures that are naturalized in any particular society. Mauss took the word 'habitus' from Aristotle in order to capture, better than the French habitude (habit or custom), the 'acquired ability' that he wished to conceptualize (p.73). The concept of habituation was then popularized by Bourdieu (1977), who wrote of the habitus as a form of practical reason not so much expressed in embodied activities, such as posture, gait and gestures, so much as subsisting in it. Through routinely carrying out activities involving particular bodily positions and movements, what Bourdieu calls a bodily 'hexis', a person develops their social, spatial, temporal and affective orientations, and which, as 'structuring structures', are reproduced over time. Tim Ingold (2000) critiques Mauss's work for assuming an instrumental approach to the body as being put to work by a controlling mind (p.162), and thus as reducing the technical to the mechanical (p.352). By contrast, however, Talal Asad (1997) criticizes Bourdieu, for a failure to put the mind into the body. For Asad, Bourdieu's formulation of the habitus does not allow the subject reflexivity about their bodily learning. For Asad, Mauss does not treat the body as passive but as the 'self-developable means for achieving a range of human objects - from styles of physical movement... through modes of emotional being... to kinds of spiritual experience' (p.47-48).

Techniques of the body have not been an analytical lens explicitly drawn upon to study infant feeding. This is, we suggest, a missed opportunity because infant feeding is so profoundly influenced by women's sensory experiences of the practical activity of 
breastfeeding. In their Australian study, for example, Schmied and Lupton (2001) found that first-time mothers in late pregnancy subscribed quite uniformly to the dominant discourse of 'breast is best', but their initial experiences of breastfeeding first-hand - whether they felt it a pleasurable source of intimate connection, or were exhausted by the demands of the baby, the constant proximity, the physical changes in their breasts, or the pain of split nipples or engorged breasts - differentiated their subsequent trajectories and led the majority to switch irreversibly to bottle feeding. O'Connor and van Esterik (2012) identify remarkably consistent cross-cultural arrangements in the postpartum, 'cocooning' the mother with the newborn baby, so as to cut her off 'from her ordinary life and prior bodily modes while focussing the mother on developing a new bodily mode with her baby' (p.16), and suggest that we need to study breastfeeding as a 'custom' and not as part of a 'culture'.

Our studies show too that breastfeeding develops as a practice, requiring a woman to negotiate with her own 'enculturated body', as O'Connor and van Esterik put it (p.16). Carlyle, discussed above, points out that the role of tinkers such as Bianchi uncovers the tensions between social prescriptions to breastfeed, and women's practical difficulties in doing so, in a context where conceptions of the body were shifting towards a mechanical model subject to the laws of physics. Saha shows the flux in colonial Bengal as British mechanical ideas about breastfeeding meet with deep-seated Indian ideas about the maternal lactating body and breastfeeding infant in terms of humoral perception.

The techniques of the humoral 'body in balance' (Horden and Hsu, 2013) are a recurrent theme in the rest of the volume. In their study of neonatal nourishment in Pakistani Punjab, Qureshi et al. underscore the unanimous advice of community maternal and child health workers to pregnant women that they limit their consumption of heating foods, such as egg, chicken or fish, until the third trimester, so as to prevent miscarriage or early delivery. In her study of local methods of enhancing the blood in Highland Peru, Gillespie highlights how 
breast-milk may overheat, or spoil if a mother has been working in the sun and this foremilk should be expressed before feeding. Conversely, the mother's over-exposure to cold water, when washing clothes, provoked flu in an infant. This cross-over between the heating properties of foods, and the heating effects of the environment is also there in Pakistani Punjab. Later in our volume, Rahman, writing about North-Western Amaznoia, also engages with the cooling of heated bodies before consumption, including before the infant's taking of breastmilk; and this prerequisite is also apparent in the four most prevalent Gambian ethnicities in O'Neill et al.'s study, which we describe in more detail below. Further, O'Neill et al. describe how the hottest hours of the day are the ones in which malevolent dwarves are most prevalent; and how infants must be protected from 'foul wind' associated with their dwellings. Perhaps especially common to non-naturalist -and non-objectifyingepistemological ontologies, this close attention to the phenemonological experience of the humoral body may bear testment to a widespread humorism that cannot be reduced to the consequences of colonial expansion or scholarly dissimination, but is indeed of near panhuman pertinence to neonatal and maternal health (e.g. Butt-Colson and de Armellada, 1983, Laderman, 1987, White, 2004, O'Connor and van Esterik, 2012).

O'Neill et al.'s examination of postnatal protection rituals in the Gambia develops the insight into infant feeding as a technique that is not only nutritive but also spiritual. Rural mothers in the Gambia do not immediately place the newborn on the breast but nourish the baby first with a set of other substances in order to protect it from spiritual attack. After cutting the cord, the newborn is first washed, to remove the blood and other surrounds which accentuate its vulnerability, and it is then fed honey and a Quranic potion to protect it from spirits. This is made by a marabout, who will write a verse of the Quran on a blackboard, wipe it off with a cloth which is then decocted in water; alternatively, if written on paper, the paper itself is infused in a bottle of water and perfume. The surface of the newborn's stomach 
is thus understood to absorb not only nutrients but also these fortifying spiritual qualities. Mothers rub the lips, tummies and undertongue of the baby with kola juice, to ensure that the child will grow up to be a deft orator. Only then, and after infant and mother cleansing in the homestead, will a newborn be put to the breast. In the past, newborns would be fed animal milk or given to a woman with a mature milk supply during the first few days, but health workers today are trying to encourage women to reject these practices and breastfeed immediately. Nonetheless, the cultural significance of spiritual illness is such that their admonitions to breastfeed as early as possible and leave these Quranic potions are ineffective. Whilst all are concerned with saving the lives of infants, O'Neill et al. highlight the key prerogative of parents to be the making of a new member of society. Thus these proscriptions are key to securing in aiding an infant's rite-of-passage into the community, with neonatal vulnerability coming to an end seven days post-birth, with the naming ritual.

Skill, which entails 'qualities of care, judgement and dexterity', is a property 'not of the individual human body as a biophysical entity, a thing in-itself, but of the total field of relations constituted by the presence of the organism-person, indissolubly body and mind, in a richly structured environment. That is why the study of skill, in my view, not only benefits from, but demands an ecological approach' (Ingold 2000, p.353, emphasis in the original). It is within this tenor that Bird-David (2008) has questioned the use of the term 'nurture', which she suggests may 'allure readers to presuppose that child feeding is about one-way, up-down giving of food to children; that it is entangled with rearing, training, protecting and loving the children, and with the parents' and the children's innate needs; and that it lasts until the children grow up and can take care of themselves' (p.545). As a result, for the Indian Nayaka among whom she worked - amongst whom children do a lot of nurturing too - 'sharing', rather than nurturing, may be a less loaded term of description. Echoing Foucaudian normalization and the bourgeois emphasis on a safe and controlled adult environment, Bird- 
David brings to the fore the Nayaka's relational and 'giving environment', juxtaposing the controlling role entailed in serving food and 'playing mother' in 1980s Cambridge with Nayaka's children's free access and self-service, as well as collaboration in collecting and preparing foods. For the latter, 'mothercraft' is part and parcel of a greater ethos of living together in an animist ontology which engenders a coeval relationship between adults and children. Drawing from this, Rahman, in our final contribution, argues that feeding techniques emerge as part of a mindful mode of being, a key part of this larger logic of intersubjective relationality, and the humoral perception of which it forms part.

Rahman's paper describes food shamanism among Warakena dwellers of the Xie river in North-West Amazonia in Brazil. When new elements are introduced into a baby's diet, these are ritually managed so as to ensure that food is 'life-enhancing, rather than lifedevouring'. Feeding is perceived in humoral terms, which Rahman explicates as an understanding of the body in need of balance, rather than a rigid taxonomy of substances, places or actions. Recalling Saha, Gillespie and Qureshi et al.'s descriptions of the humoral perception of lactation, new mothers' milk production is boosted through the consumption of heating karibé (a manioc bread drink) and caldo (a poultry broth). Given the hot climate, young babies need to be cooled down before they eat. They are washed in river water prior to being offered any oral stimulation or food, including the breast. This serves to cool them down, but Rahman shows that river water - understood to be absorbed through the skin, like the heating oils that are massaged into weak newborns in Pakistani Punjab - deserves to be seen as a constituent part of infant nourishment as well. As the baby grows, new elements introduced to her diet are initiated with a blessing spell by an elder of the family, to forestall attacks by ancestral spirit animals. All such practices may be understood as indigenous perceptions of humorism. Caring techniques, whilst good for health, also engender the enfolding of power relations into the human organism itself (see Rahman, 2016). 
Recalling Tomori's (2014) study of the significance of husbands/fathers in American women's breastfeeding trajectories, and Maher's (2015) reminder that the collaboration of husbands/fathers was often crucial in deciding whether and for how long women will breastfeed, given the existence of a widespread taboo on sexual intercourse during breastfeeding in historical Europe, Rahman's study offers a fascinating supplement to this discussion, namely the Amerindian institution of the couvade. In the post-birth period, Warakena husbands/fathers are expected to follow the same dietary restrictions as new mothers, essentially following the pregnancy diet of bland and less potent pirá miri (little fish) with manioc bread. This period of fasting is understood to be essential, lest the ancestral spirit animals be angered, and both parents seek to have these forbidden substances blessed by a respected shaman to ensure their own and their infant's health prior to their consumption a week post-birth. Husbands/fathers are also prohibited from all strong actions, objects and sounds in the immediate post-birth, as well as overly cool or radically heated social states such as hunting, hammering, hitting or playing football. We will leave it as an open question whether studies such as Tomori's are documenting what Françoise Barbira-Freedman (2014) has called a 'neo-couvade' in cosmopolitan trends of co-parenting.

What we have in the final contributions to our volume is a deep scholarly attentiveness to the encultured body. This is, we suggest, a fruitful way of understanding the tacit cultural logics of infant feeding. Time after time, medically-oriented studies document and identify local understandings of infant feeding as problematic obstacles for state and international intervention, but the underlying epistemologies remain unfathomed. As a counter-argument, to play devil's advocate and speak to the divergent perspectives on infant feeding that are held among us, it might be argued by scholars like Paul Farmer (1999) that deep attention to cultural difference distracts us from engaging in a politicized reading of culture, and from understanding the material effects of social inequality and inequality in 
access to health care on maternal and infant bodies. On this note, Didier Fassin (2009) reminds us that what he calls 'bioinequalities' are as much a part of Foucauldian biopolitics as pastoral care for populations. For Foucault, biopolitics was the management of the thriving of some and simultaneously the failing of others. Rahman notes, for example, that one or more infant deaths are standard among the Xie Warekena. The thrust of her paper is not to decry the feeding and caring practices of the Warekena as irresponsible or ignorant, but to understand them as techniques of the enculturated body, questioning exactly what is at risk: the saving of lives at the expense of an affirmation of a whole - and healthful - way of being? (Kaufert and O'Neil, 1993). Perhaps what is at stake here is what constitutes a life worth living. We could equally suggest that, in the case of the Warekena, this shows us a tacit biopolitical imperative of the Brazilian state, as with their lacklustre efforts to serve the Warekena through mobile health camps. These are long-standing tensions in the historical and anthropological study of health and healing. Recently, Alice Street (2014) has offered a principled argument that examining questions of power is not precluded by 'deep cultural comparison'. We hope that this volume offers similarly productive food for thought for those studying infant feeding, as well as fodder for future dialogue along these lines.

\section{Bibliography}

Apple, R. (1987). Mothers and Medicine: A Social History of Infant Feeding, 1890-1950. Madison: University of Wisconsin Press.

Asad, T. (1997). Remarks on the Anthropology of the Body. In S. Coakley (Ed.) Religion and the Body (pp. 42-52). Cambridge: Cambridge University Press.

Avishai, O. (2007). Managing the Lactating Body: The Breastfeeding Project in the Age of Anxiety. In P. Liamputtong (Ed.) Infant Feeding Practices: A Cross-Cultural Perspective (pp. 23-38). Dordrecht: Springer. 
Ball, H. \& Russell, C. (2012). Night-Time Nurturing: An Evolutionary Perspective on Breastfeeding and Sleep. In D. Narvaez, J. Panksepp, A. Schore \& T. Gleason (Eds), Evolution, Early Experience and Human Development: From Research to Practice and Policy (pp. 241-61). Oxford: Oxford University Press.

Barbira-Freedman, F. (2014). Amazonian Couvade to Neo-Couvade in Cosmopolitan Trends of Co- Parenting: A Comparative Analysis. Paper presented at Seminars on Infant feeding: nourishment and nurture, 1st December, Fertility and Reproduction Studies Group, University of Oxford. https://podcasts.ox.ac.uk/amazonian-couvade-neocouvade-cosmopolitan-trends-co-parenting-comparative-analysis

Bartlett, A. (2010a). Breastfeeding and Time: In Search of a Language for Pleasure and Agency. In R. Shaw \& A. Bartlett (Eds), Giving Breastmilk: Body Ethics and Contemporary Breastfeeding Practices (pp. 222-35). Toronto: Demeter Press.

Bartlett, A. (2010b). Babydaze: Maternal Time. Time \& Society, 19(March), 120-32. Bentley, A. (2014). Inventing Baby Food: Taste, Health and the Industrialization of the American Diet. Berkeley: University of California Press.

Bird-David, N. (2008). Feeding Nayaka Children and English Readers: A Bifocal Ethnography of Parental Feeding in 'the Giving Environment'. Anthropological Quarterly, 81(3), 523-50.

Blum, L. (1993). Mothers, Babies, and Breastfeeding in Late Capitalist America: The Shifting Contexts of Feminist Theory. Feminist Studies, 19(2), 291-311.

Bourdieu, P. (1977). Outline of a Theory of Practice. Cambridge: Cambridge University Press.

Butt-Colson, A. \& de Armellada, C. (1983). An Amerindian Derivation for Latin American Creole Illnesses and Their Treatment. Social Science and Medicine, 171229-48. 
Carsten, J. (1997). The Heat of the Hearth: The Process of Kinship in a Malay Fishing Village. Oxford: Clarendon Press.

Cassidy, T. (2015). Historical Ethnography and the Meanings of Human Milk in Ireland. In T. Cassidy \& A. El Tom (Eds), Ethnographies of Breastfeeding: Cultural Contexts and Confrontations (pp. 45-58). London: Bloomsbury.

Cassidy, T. \& El Tom, A. (Eds) (2015). Ethnographies of Breastfeeding: Cultural Contexts and Confrontations. London: Bloomsbury.

Chatterjee, P. (1993). The Nation and Its Fragments. Princeton: Princeton University Press.

Conrad, P. \& Schneider, J. (1980). Deviance and Medicalization: From Badness to Sickness. St Louis: Mosby.

Davis-Floyd, R. (1990). The Role of Obstetrical Rituals in the Resolution of Cultural Anomaly. Social Science and Medicine, 31(2), 175-89.

Davis-Floyd, R. \& Sargent, C. (Eds) (1997). Childbirth and Authoritative Knowledge: CrossCultural Perspectives. Berkeley: University of California Press.

Davis, A. (2011). 'When I Was Young You Just Went and Asked Your Mother.' the Changing Role of Friends and Kin in the Transmission of Knowledge About Maternity in Post-1945 Britain. Medizin, Gesellschaft und Geschichte, 4015-34.

de Graeve, K. \& Longman, C. (2013). Intensive Mothering of Ethiopian Adoptive Children in Flanders, Belgium. In C. Faircloth, D. Hoffman \& L. L. (Eds), Parenting in Global Perspective: Negotiating Ideologies of Kinship, Self and Politics (pp. London: Routledge.

Dykes, F. (2006). 'Supply' and 'Demand': Breastfeeding as Labour. Social Science and Medicine, 60(10), 2283-93.

Dykes, F. \& Hall-Moran, V. (Eds) (2009). Infant and Young Child Feeding. Oxford. 
Faircloth, C. (2013). Militant Lactivism? Infant Care and Maternal Identity. Oxford: Berghahn.

Farmer, P. (1999). Infections and Inequalities: The Modern Plague. Berkeley: University of California Press.

Fassin, D. (2009). Another Politics of Life Is Possible. Theory, Culture and Society, 26(5), 44-60.

Fildes, V. (1986). Breasts, Bottles and Babies: A History of Infant Feeding. Edinburgh: Edinburgh University Press.

Foucault, M. (1975). Discipline and Punish. New York: Vintage Books.

Foucault, M. (1984). The History of Sexuality: An Introduction. In P. Rabinow (Ed.) The Foucault Reader (pp. London: Penguin Books.

Giles, F. (2010). From 'Gift of Loss' to Self Care: The Significance of Induced Lactation in Takashi Miikes' Visitor Q. In R. Shaw \& A. Bartlett (Eds), Giving Breastmilk: Body Ethics and Contemporary Breastfeeding Practice (pp. 236-49). Toronto: Demeter Press.

Godbout, J. (1998). The World of the Gift. Montreal: McGill-Queen's University Press. Golden, J. (2001). A Social History of Wet Nursing in America: From Breast to Bottle Cambridge: Cambridge University Press.

Gow, P. (1989). The Perverse Child: Desire in a Native Amazonian Subsistence Economy. Man, 24(4), 567-82.

Hausman, B. (2004). The Feminist Politics of Breastfeeding. Australian Feminist Studies, 19(45), 273-85.

Hewlett, B., Lamb, M., Leyendecker, B. \& Schölmerich, A. (2000). Internal Working Models, Trust, and Sharing among Foragers. Current Anthropology, 41(2), 287-97. 
Horden, P. \& Hsu, E. (Eds) (2013). The Body in Balance: Humoral Medicines in Practice. Oxford: Berghahn.

Hunt, N. (1997). 'Le Bebe En Brousse': European Women, African Birth Spacing, and Colonial Intervention in Breast Feeding in the Belgian Congo. In F. Cooper \& A. L. Stoler (Eds), Tensions of Empire Colonial Cultures in a Bourgeois World (pp. 287321). Berkeley: University of California Press.

Ingold, T. (2000). The Perception of the Environment: Essays on Livelihood, Dwelling and Skill. London: Routledge.

Jordan, B. (1978). Birth in Four Cultures: A Cross-Cultural Investigation. Montreal: Eden Press.

Kaufert, P. \& O'Neil, J. (1993). Analysis of a Dialogue on Risks in Childbirth: Clinicians, Epidemiologists, and Inuit Women. In S. Lindenbaum \& M. Lock (Eds), Knowledge, Power and Practice: The Anthropology of Medicine and Everyday Life (pp. Berkeley: University of California Press.

King, J. \& Ashworth, A. (1987). Historical Review of the Changing Patterns of Infant Feeding in Developing Countries: The Case of Malaysia, the Caribbean, Nigeria, and Zaire. Social Science and Medicine, 25(12), 1307-20.

Laderman, C. (1987). Destructive Heat and Cooling Prayer: Malay Humoralism in Pregnancy, Childbirth and the Postpartum Period. Social Science and Medicine, 25(4), 357-65.

Liamputtong, P. (Ed.) (2007). Infant Feeding Practices: A Cross-Cultural Perspective. Dordrecht: Springer.

Mabilia, M. (2002). Breast Feeding and Sexuality: Behaviour, Beliefs and Taboos among the Gogo Mothers Oxford: Berghahn. 
Mabilia, M. (2005). Breast Feeding and Sexuality: Behaviour, Beliefs and Taboos among the Gogo Mothers Oxford: Berghahn.

Maher, V. (Ed.) (1992). The Anthropology of Breast-Feeding: Natural Law or Social Construct? Oxford: Berg.

Maher, V. (2015). Women and Children First? Gender, Power, and Resources, and Their Implications for Infant Feeding. In T. Cassidy \& A. El Tom (Eds), Ethnographies of Breastfeeding: Cultural Contexts and Confrontations (pp. 187-208). London: Bloomsbury.

Martin, E. (1987). The Woman in the Body: A Cultural Analysis of Reproduction. Boston: Beacon Press.

Mauss, M. (1969). The Gift: Forms and Functions of Exchange in Archaic Societies. London: Routledge and Kegan Paul.

Mauss, M. (1973). Techniques of the Body. Economy and Society, 2(1), 70-88.

Millard, A. (1990). The Place of the Clock in Pediatric Advice: Rationales, Cultural Themes, and Impediments to Breastfeeding. Social Science and Medicine, 31(2), 211-21.

O'Connor, R. \& van Esterik, P. (2012). Breastfeeding as Custom Not Culture: Cutting Meaning Down to Size. Anthropology Today, 28(5), 12-16.

Obermeyer, C. \& Castle, S. (1996). Back to Nature? Historical and Cross-Cultural Perspectives on Barriers to Optimal Breastfeeding. Medical Anthropology, 17(1), 3963.

Overing, J. (1989). Personal Autonomy and the Domestication of Self in Piaroa Society. In G. Jahoda \& I. M. Lewis (Eds), Acquiring Culture: Cross Cultural Studies in Child Development (pp. 169-92). London: Croon Helm.

Palmer, G. (1988). The Politics of Breastfeeding. London: Pandora. 
Pooley, S. \& Qureshi, K. (Eds) (2016). Parenthood between Generations: Transforming Reproductive Cultures. Oxford: Berghahn.

Rahman, E. (2016). Intergenerational Mythscapes and Infant Care in Northwestern Amazonia. In S. Pooley \& K. Qureshi (Eds), Parenthood between Generations: Transforming Reproductive Cultures (pp. 181-206). Oxford: Berghahn.

Schmied, V. \& Lupton, D. (2001). Blurring the Boundaries: Breastfeeding and Maternal Subjectivity. Sociology of Health and Illness, 23(2), 234-50.

Shaw, R. \& Bartlett, A. (Eds) (2010). Giving Breastmilk: Body Ethics and Contemporary Breastfeeding Practices. Toronto: Demeter Press.

Shusterman, R. (2000). Somaesthetics and Care of the Self: The Case of Foucault. The Monist, 83(4), 530-51.

Stoler, A. (1995). Race and the Education of Desire: Foucault's History of Sexuality and the Colonial Order of Things. Durham: Duke University Press.

Street, A. (2014). When Comparison Comes First: Reflections on Theory in Medical Anthropology. Medicine, Anthropology, Theory, 1(1), 34-41.

Stuart-Macadam, P. \& Dettwyler, K. (Eds) (1995). Breastfeeding: Biocultural Perspectives. New York: Aldine de Gruyter.

Tomori, C. (2014). Nighttime Breastfeeding: An American Cultural Dilemma. Oxford: Berghahn.

van Esterik, P. (1994). Breastfeeding and Feminism. International Journal of Gynegology and Obstetrics, 47S41-54.

Vilaça, A. (2002). Making Kin out of Others in Amazonia. Journal of the Royal Anthropological Institute, 8(2), 347-65.

White, P. (2004). Heat, Balance, Humors, and Ghosts: Postpartum in Cambodia. Health Care For Women International, 25(2), 179-94. 
Wolf, J. (2006). What Feminists Can Do for Breastfeeding and What Breastfeeding Can Do for Feminists. Signs, 31(2), 397-424.

Wolf, J. (2011). Is Breast Best? Taking on the Breastfeeding Experts and the New High Stakes of Motherhood. New York: New York University Press. 